\title{
Study on Water Flow Control of Urban Road through Water Permeable Road
}

\author{
Chaocheng Zheng* \\ Nanjing Vocational Institute of Transport Technology, Nanjing 211188, China. \\ *zccnau@126.com
}

Keywords: Permeable pavement; Runoff; Non-point source pollution.

\begin{abstract}
This study investigated grass brick, pervious concrete and permeable brick and other different types of permeable pavement by indoor simulation (low impact development technology, LID) cut path flow, network delay arrival time and reduce the peak flow of network peak flow effect; at the same time is analyzed under different conditions of permeable face removal effect of different types of pollutants.
\end{abstract}

\section{Materials and Methods}

\subsection{Experimental Materials.}

This study was conducted in the laboratory simulation experiment, selected the commonly used surface layer material in practice, mainly grass brick, pervious concrete, water permeable brick, according to the actual pavement construction specification for building simulation device, using rain water distribution uniformity simulation device of different intensity, explore the different conditions of permeable facing the control effect of storm water runoff.

\subsection{Experimental Device}

\subsubsection{Permeable Pavement Simulator}

Water permeable concrete device: a pervious concrete simulation device is a column with a specification of 16 plus $16 \mathrm{~cm}$ setting a water outlet at the bottom, with an aperture of $2.5 \mathrm{~cm}$. The gap between the surface layer and the container is filled with glass glue to prevent the rain from sliding down the wall of the container.

Grass brick device size is $50 \mathrm{~cm} * 20 \mathrm{~cm} * 60 \mathrm{~cm}$, set up four water outlets at the bottom of the container, the aperture is $2.5 \mathrm{~cm}$. The gap between the grass brick and container with soil compaction has been prepared to fill. The thickness of the soil filled in the grass brick in $5 \mathrm{~cm}$, and planting herbs in them.

Water permeable brick device: the size of the self-permeable brick and self-permeable brick is the size of the device with $44 \mathrm{~cm} * 22 \mathrm{~cm} \times 60 \mathrm{~cm}$ and $50 \mathrm{~cm} \times 25 \mathrm{~cm} \times 60 \mathrm{~cm}$, set four outlet ports at the bottom of the container, with a pore size of $2.5 \mathrm{~cm}$. The gap between each block is $0.3 \mathrm{~mm}$, and the middle sands are filled in the middle of the gap. The gap between the permeable brick and the glass container is filled with glass glue to prevent the rain from falling down the wall of the container.

\subsubsection{Water Distribution Device}

In indoor simulated rainfall, factors such as raindrop size, shape, landing speed and evenness should be considered. At the same time, we should take into account the factors such as rainfall area and water consumption. The purpose of this experiment is to investigate permeable face city road runoff control and explore the role in the reduction of runoff infiltration of non-point source pollution in the process, without considering the scouring effect of rainfall on the road, so in the simulation of rainfall can be neglected when the raindrop size and landing speed on the experimental results, as long as the water distribution can be achieved the purpose of the experiment. On the basis of the above analysis, taking into account the smaller device area, a water distributor suitable for 
experiment is developed based on the indoor experimental device such as pinhole type rain collector and Jorge Rodriguez-Hernandez.

\subsection{Experimental Method}

\subsubsection{Experimental Design}

In this experiment, the effect of rainfall intensity, dry period and thickness of structure layer on the effect of water permeable pavement-controlled runoff was mainly investigated. After the experiment, the rainfall intensity was changed by adjusting the water transport volume of the peristaltic pump. The amount of water in the drainage tube was taken, and the amount of water was 120 min for each rainfall. After the drainage pipe begins to drain, the amount of drainage is measured every five minutes until the discharge in the drainage pipe is less than $0.2 \mathrm{ml} / \mathrm{min}$. The experimental water in this stage is the tap water in the laboratory. Based on the actual rainfall data, after rainfall intensity was selected, the rainfall pattern was allocated by rainfall pattern in Chicago, and the rainfall curve was obtained, and the simulated rainfall was simulated according to the rainfall curve listed in Table 1.

Table 1. Rainfall statistics in Nanjing between 2011 and 2015

\begin{tabular}{cccc}
\hline Type of rainfall & Rainfall intensity $(\mathrm{mm} / \mathrm{h})$ & Rainfall $(\mathrm{mm})$ & Quantity (field) \\
\hline Heavy rainfall & $\geqslant 20$ & $\geqslant 20$ & 9 \\
Medium intensity rainfall & $10 \leqslant \mathrm{i} \leqslant 20$ & $\geqslant 10$ & 31 \\
Small intensity rainfall & $\mathrm{i} \leqslant 10$ & - & 185 \\
\hline
\end{tabular}

According to the statistical results of actual rainfall data, after the intensity of rainfall is selected, the rainfall pattern is allocated by using the rainfall pattern of Chicago (Table 2), and the rainfall curve is obtained, and the simulated rainfall is simulated according to the rainfall curve.

Table 2. 120 min rain form

\begin{tabular}{lcccccc}
\hline Time period (min) & $0-5$ & $5-10$ & $10-15$ & $15-20$ & $20-25$ & $25-30$ \\
\hline Distribution value & 0.012 & 0.013 & 0.016 & 0.018 & 0.022 & 0.028 \\
Time period (min) & $30-35$ & $35-40$ & $40-45$ & $45-50$ & $50-55$ & $55-60$ \\
Distribution value & 0.037 & 0.053 & 0.088 & 0.174 & 0.137 & 0.081 \\
Time period (min) & $60-65$ & $65-70$ & $70-75$ & $75-80$ & $80-85$ & $85-90$ \\
Distribution value & 0.061 & 0.046 & 0.036 & 0.03 & 0.026 & 0.021 \\
Time period (min) & $90-95$ & $95-100$ & $100-105$ & $105-110$ & $110-115$ & $115-120$ \\
Distribution value & 0.019 & 0.017 & 0.014 & 0.013 & 0.012 & 0.011 \\
\hline
\end{tabular}

The rainfall pattern of simulated rainfall is obtained by the rainfall distribution table. The characteristics of simulated rainfall are shown in Table 3.

Table 3. Simulated rainfall characteristics

\begin{tabular}{cccc}
\hline & Average rainfall intensity & Maximum rainfall intensity & Rain period \\
\hline small rain & $5 \mathrm{~mm} / \mathrm{h}$ & $21 \mathrm{~mm} / \mathrm{h}$ & $120 \mathrm{~min}$ \\
Medium intensity rainfall & $10 \mathrm{~mm} / \mathrm{h}$ & $42 \mathrm{~mm} / \mathrm{h}$ & $120 \mathrm{~min}$ \\
Heavy rainfall & $20 \mathrm{~mm} / \mathrm{h}$ & $84 \mathrm{~mm} / \mathrm{h}$ & $120 \mathrm{~min}$ \\
\hline
\end{tabular}

To sum up, the experimental conditions of this stage are determined as shown in Table 4.

\subsubsection{Analysis Method.}

The experimental water quality indexes are chemical oxygen demand (COD), total phosphorus (TP), total nitrogen (TN) and suspended particulate matter (SS). 
Table 4. Experimental condition

\begin{tabular}{cccc}
\hline & Rainfall intensity $(\mathrm{mm} / \mathrm{h})$ & Dry period & Base thickness $(\mathrm{mm})$ \\
\hline 1 & 5 & 1 & 150 \\
2 & 10 & 1 & 150 \\
3 & 20 & 1 & 150 \\
4 & 10 & 3 & 150 \\
5 & 10 & 5 & 150 \\
6 & 10 & 1 & 200 \\
7 & 10 & 1 & 250 \\
\hline
\end{tabular}

\section{Results and Discussion}

\subsection{Effect of Runoff Control}

After rainfall occurs, the rainwater that falls on the permeable road will leak or turn into runoff. Part of the rainwater will be infiltrated into the soil base, and the rainwater that cannot penetrate into the soil foundation will be drained away in the drainage pipe. Under different rainfall intensity in Table 5, the effect of reducing runoff by water permeable road surface is obvious. When no other runoff reaches the permeable road surface, when the maximum rainfall intensity is $84 \mathrm{~mm} / \mathrm{h}$, there is no runoff on the permeable pavement surface, and the runoff is always 0 . Therefore, the permeable pavement can control the surface runoff.

Table 5. Experimental condition

\begin{tabular}{ccccc}
\hline & Rainfall/mL & pipe drainage & rainfall infiltration and evaporation & runoff \\
\hline Grass brick $(5 \mathrm{~mm} / \mathrm{h})$ & 950 & 560 & 380 & 0 \\
Self-permeable brick $(5 \mathrm{~mm} / \mathrm{h})$ & 1248 & 970 & 280 & 0 \\
Self-impermeable brick $(5 \mathrm{~mm} / \mathrm{h})$ & 1000 & 700 & 285 & 0 \\
Permeable concrete $(5 \mathrm{~mm} / \mathrm{h})$ & 171.5 & 126 & 50.8 & 0 \\
Grass brick $(10 \mathrm{~mm} / \mathrm{h})$ & 1921 & 1540 & 347 & 0 \\
Self-permeable brick $(10 \mathrm{~mm} / \mathrm{h})$ & 2500 & 2164 & 312 & 0 \\
Self-impermeable brick $(10 \mathrm{~mm} / \mathrm{h})$ & 2000 & 1754 & 221 & 0 \\
Permeable concrete $(10 \mathrm{~mm} / \mathrm{h})$ & 350 & 284 & 70 & 0 \\
Grass brick $(20 \mathrm{~mm} / \mathrm{h})$ & 3791 & 3435 & 365 & 0 \\
Self-permeable brick $(20 \mathrm{~mm} / \mathrm{h})$ & 4980 & 4640 & 360 & 0 \\
Self-impermeable brick $(20 \mathrm{~mm} / \mathrm{h})$ & 4000 & 3660 & 330 & 0 \\
Permeable concrete $(20 \mathrm{~mm} / \mathrm{h})$ & 710 & 650 & & \\
\hline
\end{tabular}

During the experiment, three rainfall experiments were conducted, the dry period was 1 days, and the rainfall intensity was $5 \mathrm{~mm} / \mathrm{h}, 10 \mathrm{~mm} / \mathrm{h}, 20 \mathrm{~mm} / \mathrm{h}$. The maximum instantaneous rainfall intensity of each simulated rainfall was $21 \mathrm{~mm} / \mathrm{h}, 42 \mathrm{~mm} / \mathrm{h}$ and $84 \mathrm{~mm} / \mathrm{h}$ respectively. Figure 1 is the result of the accumulation of water in different directions. It can be seen from the diagram that the road runoff has never appeared when the rainfall intensity is less than $84 \mathrm{~mm} / \mathrm{h}$. On the permeable pavement, the rainwater can be retained. The detained rain can supplement the groundwater by infiltration and reduce the dependence on the drainage pipe network. According to the experimental results of different intensity and different dry period, the rain retention ratio can reach $20 \%$, which greatly reduces the pressure of the pipe network and the subsequent treatment facilities. Through rainfall data, it can be found that most of the rainfall is low intensity rainfall, and the dry period is mostly longer. Therefore, in the real application process, the rainfall retention ratio will be higher. Hence, the comprehensive experiment results show that the permeable pavement can control the road runoff better and can retain a part of rainwater to replenish the groundwater, reduce the drainage pressure of the urban drainage network, and improve drainage condition. 


\subsection{Study on the Effect of Detained Rainwater on Permeable Pavement.}

When the rainfall reaches a certain amount, the water in the permeable pavement begins to drain after the water is accumulated in the permeable pavement and the drainage conditions are reached. Under different rainfall intensities, the rainfall needed to start the drainage network is different. With the increase of rainfall intensity, the rainfall needed for the drainage of the permeable pavement is reduced. From Table 5, it can be known that when the rainfall reaches $6 \mathrm{~mm}$, when the rainfall reaches to $6 \mathrm{~mm}$, the pipe network of the permeable pavement will start to drain. When the rainfall intensity is $20 \mathrm{~mm} / \mathrm{h}$, the drainage pipe will start to flow when the rainfall of its permeable brick reaches to $3.8 \mathrm{~mm}$. The main reason is that with the increase of rainfall intensity, the hydraulic pressure increases rapidly, the rain will in a relatively short period of time to the infiltration of water permeable pavement material on the bottom, infiltration time is shorter, less absorbent materials in a relatively short period of time, therefore less rainfall can be completed accumulated flow.
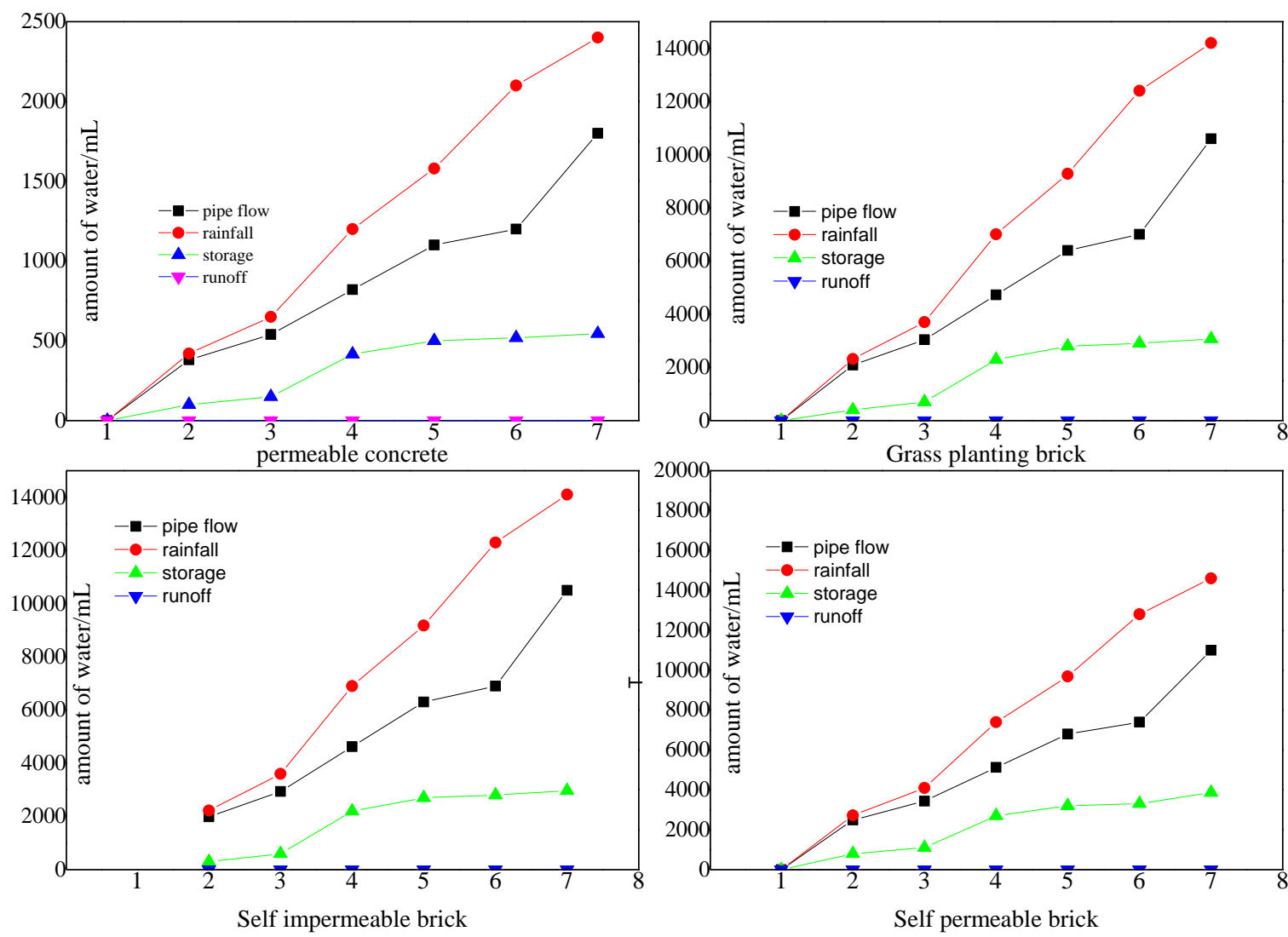

Figure 1. Water accumulation map of different direction of rain.

Table 6. Influence of rainfall intensity pervious pavement on drainage conditions

\begin{tabular}{cccc}
\hline & $5 \mathrm{~mm} / \mathrm{h}$ & $10 \mathrm{~mm} / \mathrm{h}$ & $20 \mathrm{~mm} / \mathrm{h}$ \\
\hline Grass brick & $7.9 \mathrm{~mm}$ & $7.8 \mathrm{~mm}$ & $7.9 \mathrm{~mm}$ \\
Self-permeable brick & $6.1 \mathrm{~mm}$ & $5.0 \mathrm{~mm}$ & $3.8 \mathrm{~mm}$ \\
Self-impermeable brick & $6.2 \mathrm{~mm}$ & $4.3 \mathrm{~mm}$ & $3.9 \mathrm{~mm}$ \\
Permeable concrete & $6.0 \mathrm{~mm}$ & $4.8 \mathrm{~mm}$ & $4.2 \mathrm{~mm}$ \\
\hline
\end{tabular}

In addition, dry period has a certain influence on the formation of drainage conditions. With the dry period changed from $1 \mathrm{D}$ to $5 \mathrm{D}$, corresponding to its own type of permeable brick, watertight brick, grass planting brick, previous concrete drainage when rainfall increased. With the dry period longer, permeable pavement base in water constantly leaking, reduce the water content of the rain again, the rain has been added first to walk or evaporate the water infiltration, and then began to accumulate and form the drainage, so the process of accumulation of large rainfall is completed. 
Table 7. Rainfall thickness of the permeable pavement in different dry periods.

\begin{tabular}{cccc}
\hline & 1 days of dry period & 3 days of dry period & 5 days of dry period \\
\hline Grass brick & $7.8 \mathrm{~mm}$ & $12.0 \mathrm{~mm}$ & $12.9 \mathrm{~mm}$ \\
Self-permeable brick & $5.1 \mathrm{~mm}$ & $9.1 \mathrm{~mm}$ & $10.8 \mathrm{~mm}$ \\
Self-impermeable brick & $4.2 \mathrm{~mm}$ & $5.3 \mathrm{~mm}$ & $9.9 \mathrm{~mm}$ \\
Permeable concrete & $4.9 \mathrm{~mm}$ & $7.8 \mathrm{~mm}$ & $8.2 \mathrm{~mm}$ \\
\hline
\end{tabular}

\subsection{Influence of Rainfall Intensity on the Control of R3s Pavement.}

At this stage, three simulated rainfall events are all 1 days. The rainfall intensity is $5 \mathrm{~mm} / \mathrm{h}$, $10 \mathrm{~mm} / \mathrm{h}$ and $20 \mathrm{~mm} / \mathrm{h}$ respectively. The influence of rainfall intensity on runoff control is discussed. Fig. 2-5 is the discharge curve of the drainage network under different rainfall intensity. The experimental results show that rainfall intensity has a great influence on the effect of permeable pavement on runoff control. When the intensity of rainfall increases, the time of the effluent will advance, the peak cutting rate decreases and the delay time of the flow peak of the pipe flow will be reduced.

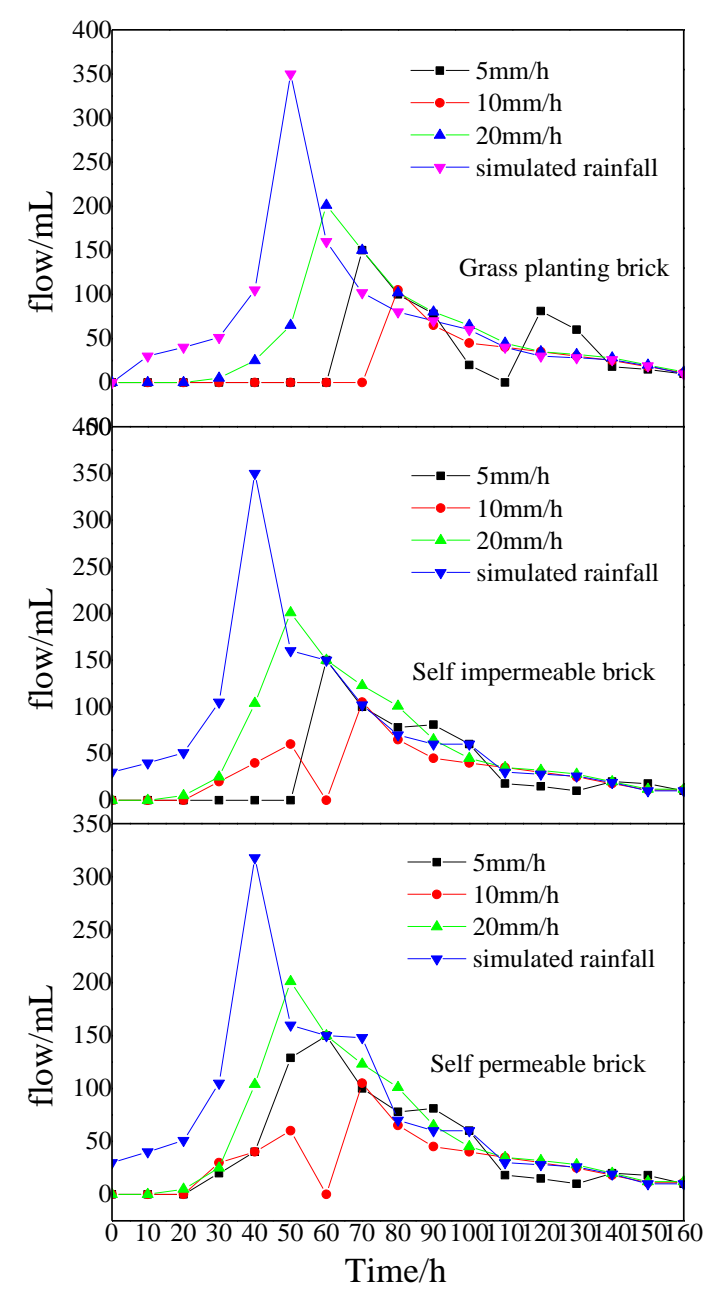

Figure 2. Influence of rainfall intensity on surface drainage of water permeable road

\section{Conclusion}

This paper focus on grass brick, pervious concrete and permeable brick and other different types of permeable pavement by indoor simulation (low impact development technology, LID) cut path flow, network delay arrival time and reduce the peak flow of network peak flow effect; at the same time is analyzed under different conditions of permeable face removal effect of different types of pollutants. 


\section{Acknowledgments}

This work was supported by a grant from Nanjing Vocational Institute of Transport Technology (JZ1711).

\section{References}

[1]. Wong T H. A stochastic approach to designing wetlands for storm water pollution control [J]. Water Science \& Technology, 1995. 32(1): 145-151.

[2]. Standalone J, Buchberger S G. Partitioning and first flush of metals in urban roadway storm water [J]. Journal of Environmental Engineering, 1997. 123(2): 134-143.

[3]. Caymanian M, Suverkropp C, et al. Characterization and prediction of highway runoff constituent event mean concentration [J]. Journal of Environmental Management, 2007. 85(2): 279-95. 